\title{
Design Parameters AfFecting Tumbling Mill Natural Frequencies
}

\author{
P. Radziszewski, Y. Y. Quan, J. Poirier \\ Department of Mechanical Engineering, McGill University, \\ 817 Sherbrooke str west, Montreal, Quebec, CANADA, H3A 2 K6 \\ peter.radziszewski@mcgill.ca
}

\begin{abstract}
Tumbling mills describe a class of mechanical systems defined by a cylindrical chamber filled with balls and/or rock that rotates around its own longitudinal axis. This class of mechanical systems is used to grind to a desired quality different material in at least three industries: mining, cement and metal powders industries (ore, clinker and metal powder). These tumbling mills range in size from small $1 \mathrm{ft}$ diameter lab mills to a $40 \mathrm{ft}$ diameter semi-autogenous industrial mill and are composed of three main interactive and interdependent elements: the mill shell, liners/lifters and charge. These three elements work together to impact energy to the mill charge through the rotational motion of the mill shell. As with any mechanical system, the natural frequency of that system is essentially dictated by its mass and stiffness. In the case of a tumbling mill, a rotating system, the natural frequency of a given mill, as seen by a stationary observer, is also a function of the rotation speed. The aim of this paper The consequence for a rotating mill, and for that matter any rotating system, is that if the natural frequency of the mill should happen to match the operating rotating speed of the mill, resonance of the mill will occur. The objective of this paper is to explore the effect of mill diameter, length on mill natural frequencies as well as outline further work.
\end{abstract}

Keywords: Tumbling mills, resonance, design

\section{Introduction}

Tumbling mills describe a class of mechanical systems defined by a cylindrical chamber filled with balls and/or rock that rotates around its own longitudinal axis. This class of mechanical systems is used to grind to a desired quality different material in at least three industries: mining, cement and metal powders industries (ore, clinker and metal powder). These tumbling mills range in size from small $1 \mathrm{ft}$ diameter lab mills to a $40 \mathrm{ft}$ diameter semi-autogenous industrial mill and are composed of three main interactive and interdependent elements: the mill shell (figure 1), liners/lifters (figure 2) and charge (figure 3). These three elements work together to impact energy to the mill charge through the rotational motion of the mill shell. The amount of energy imparted to the mill charge is dependant on the liner/lifters used as well as the worn state of these.

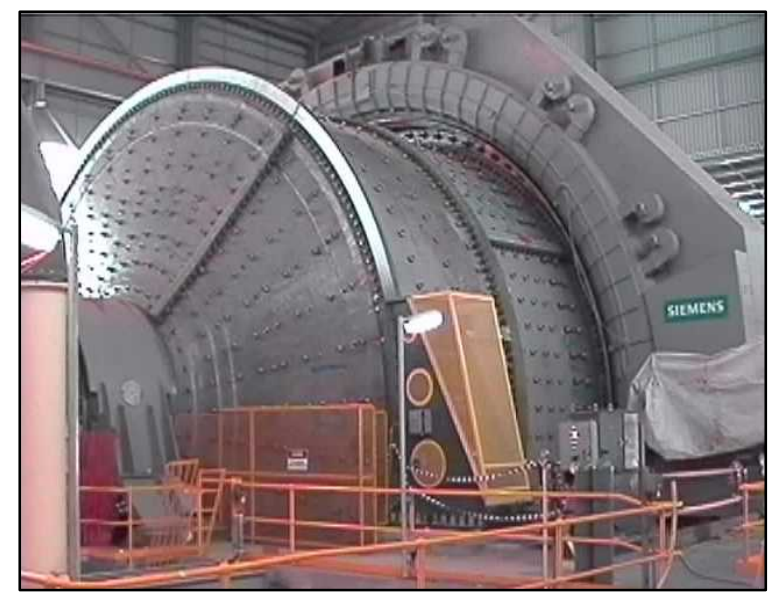

Figure 1: $40 \mathrm{ft}$ diameter SAG mill

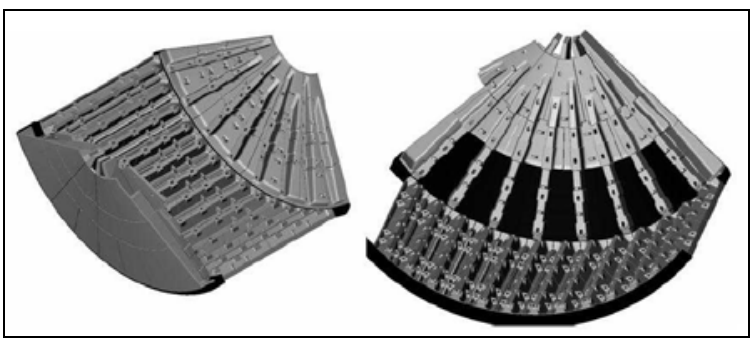

Figure 2 Typical mill liners

With the development and larger scale use of autogenous (AG) and semi-autogenous (SAG) mills in the mining industry characterized by increased mill diameter $(12 \mathrm{~m})$ [1] and varying ore breakage 
characteristics, variable mill speed drives have allowed the adjustment of mill operating speed to match the varying characteristics of the ore as well as counter the effect of liner wear [2] (figure 4). However, in the case where operating speed match the natural frequency of a given mill, the resulting resonance can shake not only the foundations lose but also create a very unsafe work environment.

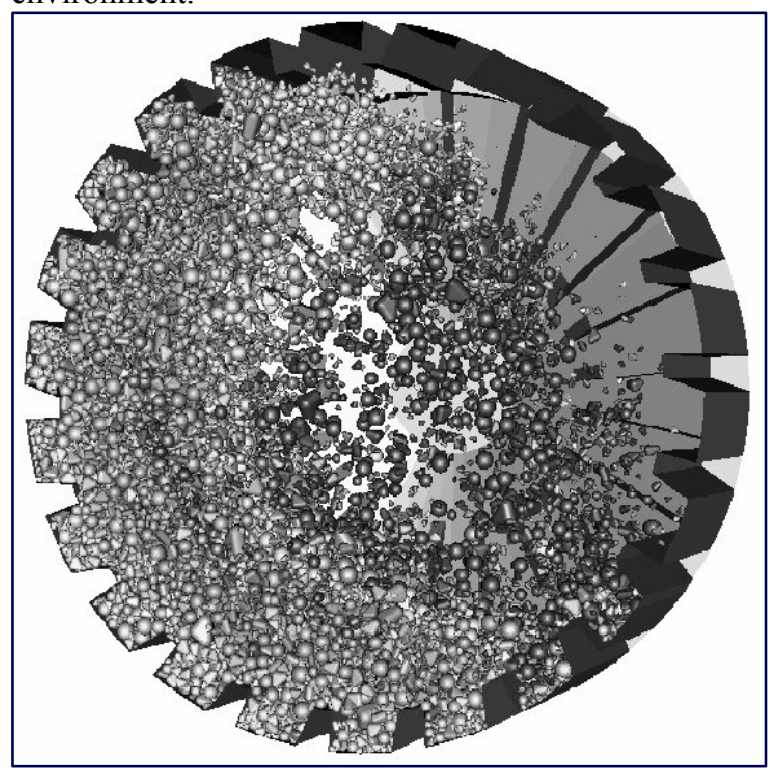

Figure 3: Simulated mill charge motion [3]

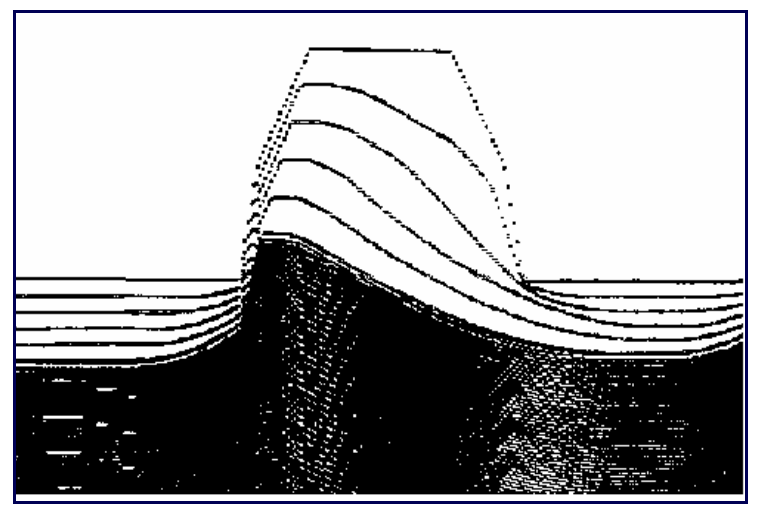

Figure 4: Liner wear profile [2]

This is the suspected case for two currently operating mills where each of these mills has addressed this problem differently. In the case of the $12 \mathrm{~m}$ mill, extra mass was added to the mill shell effectively lowering the mills' natural frequency out of the operating range. In the case of the $8 \mathrm{~m}$ diameter mill [4], the rotating speeds at which resonance occurred were block out from the possible operating range of the mill (figure 5).

It should be noted that for a tumbling mill the operating speed of a mill is defined as a function of critical speed. This speed is defined as a function of mill radius and illustrates the speed at which a particle in the mill will centrifuge:

$$
\omega_{\text {millcr }}=\sqrt{g / R_{\text {mill }}}
$$

In this latter case, the mill could only operate in the permitted ranges ramping through the blocked out speeds. Needless to same, each of these solutions to tumbling mill resonance has implications either to mill bearing and foundation integrity and maintenance or to operating efficiency.

The objective of this paper is to explore the effect of mill diameter, length on mill natural frequencies as well as outline further work.

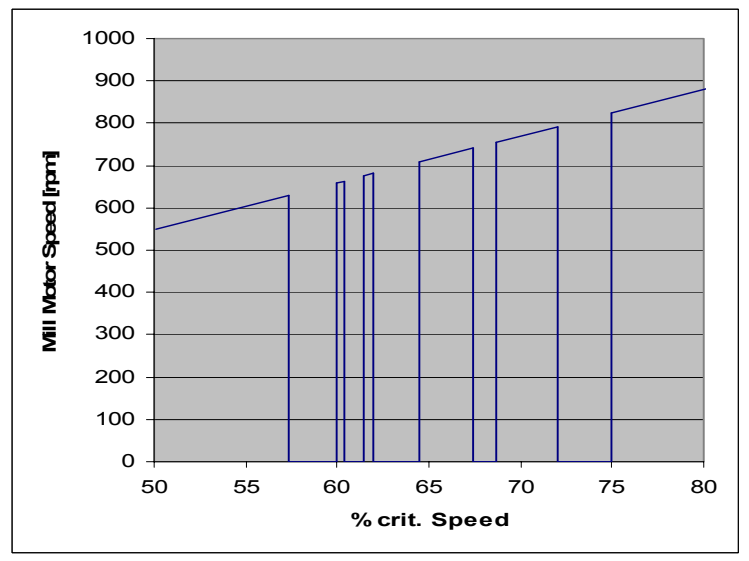

Figure 5: Mill motor speeds as a function of blocked out mill critical speeds

\section{Background}

In preparing the finite element model of a tumbling mill, two similar systems were studied: thin disk rotation and thin shelled rotating cylinders. Some of the observations made are outlined below.

\subsection{Thin Disk}

The case of the thin disk as described by the work of Mote and Szymani [5,6] illustrates that the disk vibrates transversely along nodal lines. The mode of vibration of consequence is the 2 diameter, 0 circumferences. It is this mode of vibration that often limits the rotation speed of the disk when heated [6]. The natural frequency of a thin disk rotating at speed $\omega_{\mathrm{d}}$ as seen by a stationary observer, $\omega_{\mathrm{ns}}$, can be determined by the equation (2) and illustrated in figure 6 . 


$$
\omega_{n s}=\frac{\omega_{n}}{n} \pm \omega_{d}
$$

In this case, the critical speed of the disk is the speed at which it becomes unstable. It is defined as a function of the vibration mode $n$ :

$$
\omega_{c r}=\frac{\omega_{n}}{n}
$$

At this speed the backwards traveling wave appears stationary to a stationary observer, resulting in the resonating state. The ANSYS simulation produced similar results for mode shapes and frequencies [8]. The forward and backward moving waves were illustrated using the calculation determined by Szymani, Mote [6].

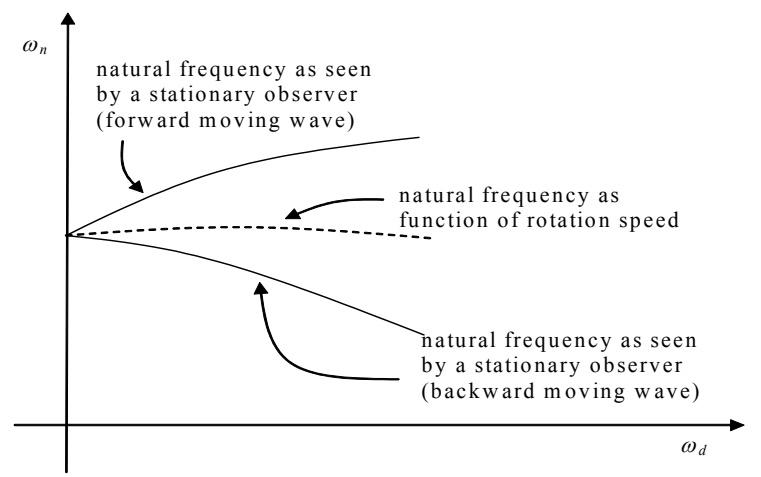

Figure 6: Rotating thin disk natural frequency as seen by a stationary observer

\subsection{Cylindrical Tube}

Since the first cylindrical shell problem was investigated by Aron in 1974, many efforts have been devoted to investigate how the Coriolis accelerations and large deformations affect the vibration modes of high speed rotating hollow cylindrical. Chen et al. use a nine nodes curvilinear super parametric finite element method to solve the problems of vibrations of high speed rotating shells of revolution [9]. They also gave the formulas for calculating the resonance frequencies of cylindrical shells. The two low resonance frequencies are showed as below:

$$
\omega_{n}=\frac{2 n}{n^{2}+1} \Omega \pm \sqrt{\frac{n^{2}\left(n^{2}-1\right)^{2}}{n^{2}+1} \frac{E k}{\rho\left(1-\mu^{2}\right)}+\frac{n^{4}+3}{\left(n^{2}+1\right)^{2}} \Omega^{2}}
$$

In this equation, the first term shows the affect of the rotation speed on the frequencies. The second is due to the normal bending stiffness, and the third caused by the Coriolis force and large deformation [9]. The goal of the cylindrical tube simulation was to reproduce the same mode shapes as those illustrated by [7].

It should be noted that this relationship is applicable to thin shelled cylinders where thin is defined as follows:

$$
\mathrm{t}_{\mathrm{sh}} / \mathrm{r}<=1 / 20(5 \%)
$$

with $t_{\text {sh }}$ is shell thickness and $r$ is tube radius.

\section{Mill Natural Frequency Calculation}

In exploring the effect of tumbling mill design parameters on mill natural frequency, it was decided to develop a model of the mill starting with the cylindrical shell followed by incrementally adding the different elements that affect mill design and performance. In the present case, only one iteration was accomplished starting with the mill as a tube of finite length and then as a capped tube.

Mill length and diameter (Table 1) was varied in such a way that mill charge volume (30\%), rotation speed (75 $\%$ crit.) and power $(7600 \mathrm{~kW})$ were constant for all cases. In this case, the mill shell was constrained at both outside edges. Thus, the natural frequency of mode 3 increased with increasing length to diameter aspect ratio (aspect) over the typical operating range of a mill.

Table 1. Simulated Mill Length and Diameter

\begin{tabular}{|l|c|c|c|c|c|c|c|}
\hline Ml Dented [m] & 854 & 9 & 10 & 11 & 8 & 7 & 6 \\
\hline Ml Lengh[m] & 42 & 375 & 288 & 22 & 503 & 7.02 & 10.32 \\
\hline Mil AspetRedio[1] & 200 & 240 & 347 & 485 & 1.59 & 1.0 & 0.58 \\
\hline
\end{tabular}

Once the models were prepare and natural frequencies determined, the forward and backward waves were calculate using equation (2) for the mill tube model results and using equation (4) for the capped tube mill model.

\subsection{Cylindrical Tube Model}

Typical mode shapes for mode 2 and 3 are found in figures 7 and 8 . The natural frequencies as a function of mill speed and aspect ratio can be found in figures 9 and 10.

For the $8.5 \mathrm{~m}$ diameter $(\mathrm{L} / \mathrm{D}=0.5$ in figure 9) mill and over a larger rotation speed range, the effect of rotation speed on the natural frequency is not that important.

When determining the forward and backward moving wave, it is possible to observe the effect on the natural 
frequency of mode 3 as seen by a stationary observer (figure 11) using equation (2).

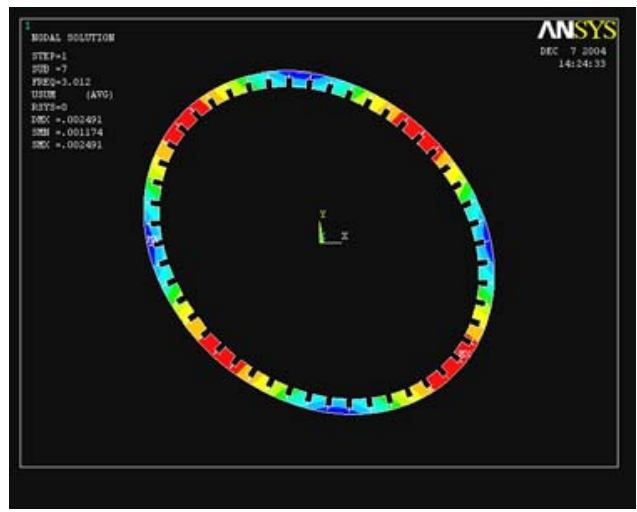

Figure 7: Mode 2 shape

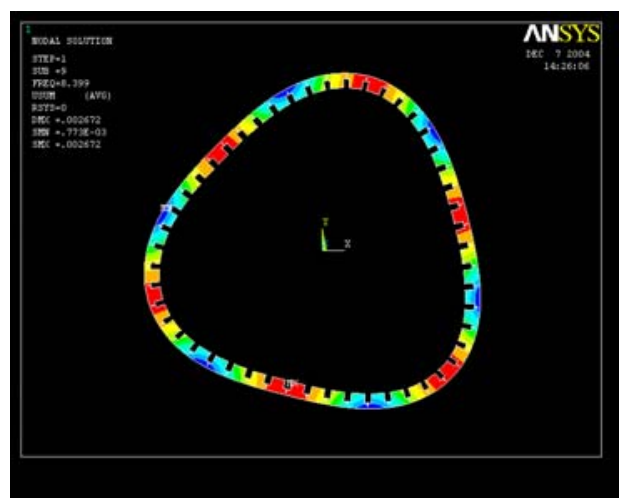

Figure 8: Mode 3 shape

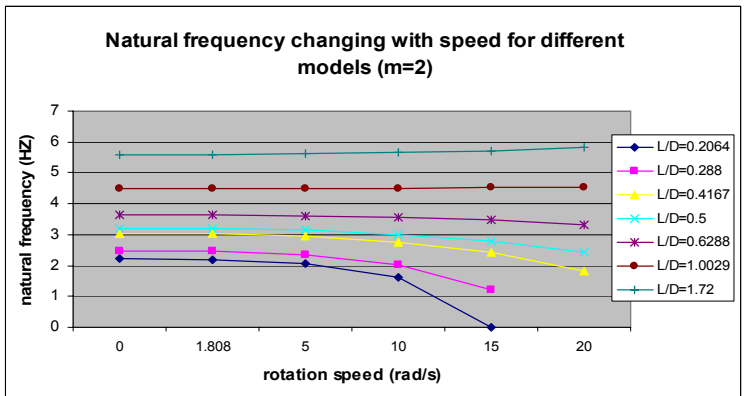

Figure 9: Mode 2 frequency as a function of speed

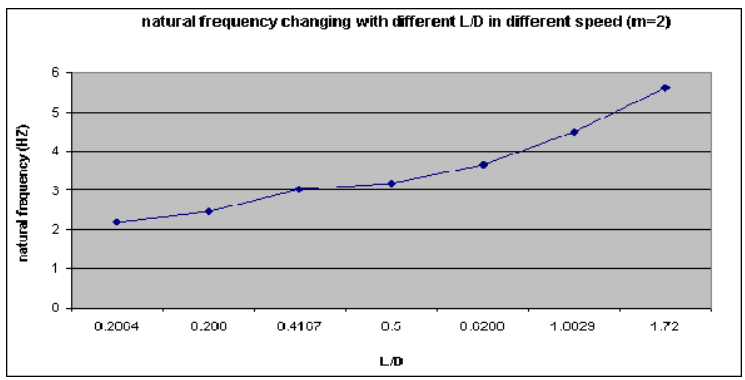

Figure 10: Mode 2 as a function of mill aspect ratio

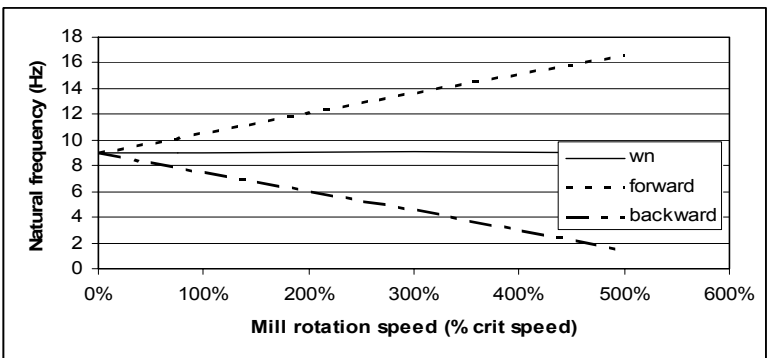

Figure 11: Forward/Backward frequency for mode 3

\subsection{Capped Cylindrical Tube Model}

After completing these initial set of simulation, the mill ends were added as shown in figure 12 and the along with the different mode shapes (see figure 13). Finally, the natural frequencies were determined for these shapes and the forward and backward wave calculated using this time equation (4) (see figure 14). It should be noted that in this case, the $t_{\mathrm{sh}} / \mathrm{r}$ ratio of equation (5) is equal to $0.095(9.5 \%)$ which is greater that the thin shell definition.

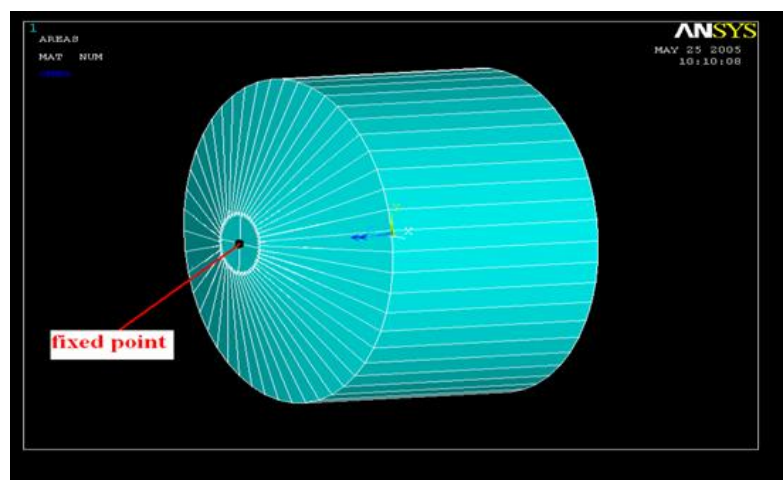

Figure 12: Mill model

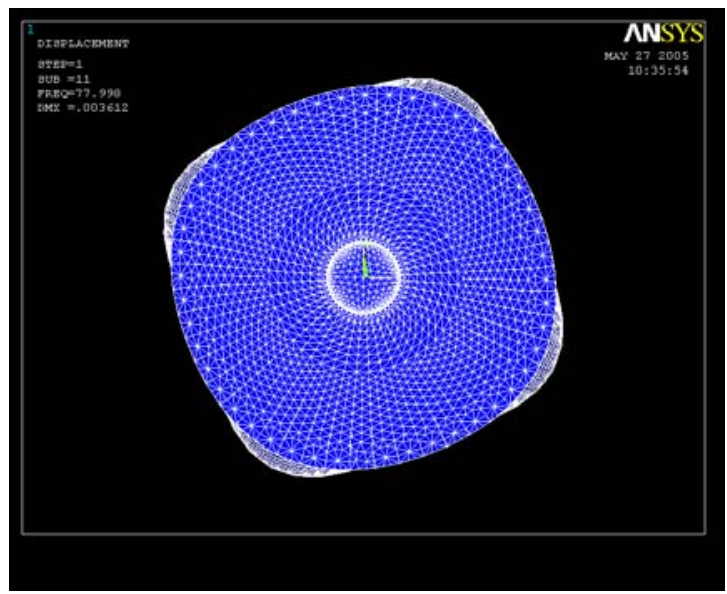

Figure 13: Mode 4 shape 


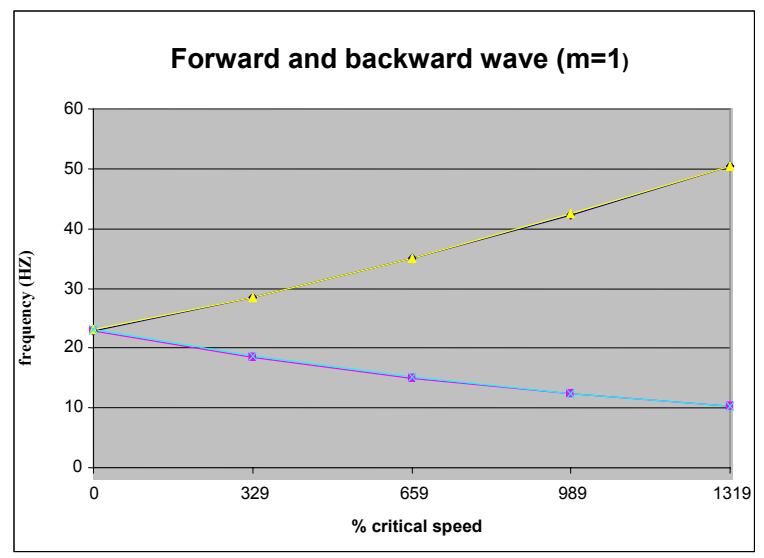

Figure 14: Mode 1 shape forward and backward waves

\section{Discussion}

The two main observations of this initial exploratory effort are that depending vibration mode, the natural frequency of that mode can either increase or decrease with the mill aspect ratio and operating speed will create a forward and backward moving wave that affects the mill natural modal frequencies as seen by a stationary observer.

However, the case simulated is that of the known mill from Brunswick Mines where resonance occurs several times between $50 \%$ and $75 \%$ critical speed as opposed to several times greater than that.

If we consider a simple mass spring system with stiffness $\mathrm{k}(\mathrm{N} / \mathrm{m})$ and mass $\mathrm{m}(\mathrm{kg})$, the natural frequency of this system is:

$$
\omega_{n}=\sqrt{\frac{k}{m}}
$$

In a more complex system, its natural frequency will be described in a more complex form. This more complex form , but essentially still be defined by some complex stiffness function over some complex mass function. This leads to the first of two explanations.

The mill system is a large, complex system where the resonance frequency depends on the whole system. Since only a part of this system is modelled and simulated, the mass is lower thus it should have higher frequencies.

The second explanation relates to the stiffness of the tumbling mill system. The mill model as developed illustrates a soled whole while the real system is a set of assembled parts. This difference would result in a stiffer system in the currently simulated case which would result in higher natural frequencies for the simulated mills.

With these modifications, it is expected that the natural frequency of simulated tumbling mills will approach that observed.

\section{Conclusion}

After investigating a rotating thin disk and then the known cases of a cylindrical tube, it was possible to explore the effect of mill length and diameter on mill natural frequencies. Further, for a known case, it was possible to investigate the evolution of mill natural frequency as a function of rotation speed.

These initial results show that the natural frequencies of a given mill as seen by a stationary observer is a function of the mill aspect ration as well as the operating speed. These two observations tend to support the idea that part of the resonance problem of the three mill cases described is the natural frequency of a given mill is a function of the design and operating parameters of that mill.

Although the tendencies in mill natural frequencies as a function of mill design (aspect ratio) and rotation speed are promising, further work is needed. Here, one can cite completing the mill model by describing it as an assembly of jointed parts, integrate pulp lifters and the mill charge. Also, experimentation on a real mill to determine and validate vibration modes is needed.

In experimenting on a real tumbling mill system, it would be necessary to consider the behaviour of the exciting force from the drive system and thus describe the whole system.

Once this work is completed and validated, it becomes possible to address avenues to correcting mill resonance in existing mills or to prevent the design and fabrication of mills that would show unwanted resonant behaviour.

It should be noted that to date only, only the mass and stiffness of the system has been considered. However, system dampening plays an important role and should be addressed in the future. 


\section{Acknowledgements}

The authors would like to thank the collaboration of Brunswick Mines for the data on blocked out speeds and NSERC for the support of this study.

\section{References}

[1] Radziszewski, P., Valery, W., (1999), CADIA SAG Mill Simulated Charge Behaviour, Canadian Mineral Processors Conference, Ottawa, January.

[2] Radziszewski, P., Tarasiewicz, S. (1993), Simulation of Ball Charge and Liner Wear, Int'l J. on Wear, Friction and Lub., 169, 77-85.

[3] Herbst, J.A., Nordell, L.K. (2001). Optimization of the Design of SAG Mill Internals Using High Fidelity Simulation, SAG 2001 Proceedings, Vancouver, British Columbia, pp. IV-150-IV-164.

[4] Orford, I, (2005), private communication, Brunswick Mines.

[5] Mote Jr., C.D., (1966) "Theory of Thermal Natural Frequency Variations in Disks" International Journal of Engineering Science, vol. 8, pp. 547-557

[6] Szymani, R., Mote Jr. C.D. (1977) "Principle Developments in Thin Saw Vibration and Control Research Part 1: Vibration of Circular Saws" Holz als Roh-und Werstoff, vol 35. pp. 219-225.

[7] Liew, K. M.; Ng, T. Y.; Zhao, X. (2002), Vibration of Axially Loaded Rotating Cross-Ply Laminated Cylindrical Shells via Ritz Method, J. Eng. Mechanics, Vol. 128, No. 9, 1001-1007.

[8] Poirier, J., Radziszewski, P. (2005), Compensating Stiffness in a Peripherally Heated Rotating Thin Disk, CANCAM, Montreal.

[9] Y. Chen, H.B. Zhao and Z. P. Shen, Journal of Sound and Vibration (1993), Vibration of High Speed rotating Shells with Calculations for Cylindrical Shells 